\title{
Proceso de deforestación en el municipio de Cherán, Michoacán, México (2006-2012)
}

\section{Deforestation process in the municipality of Cherán, Michoacán, México (2006-2012)}

\author{
María Luisa España-Boqueral* y Omar Champo-Jiménez'
}

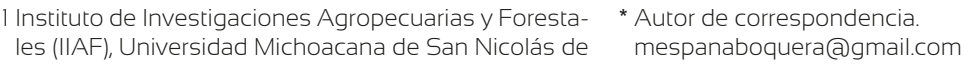

\section{RESUMEN}

La devastación de los ecosistemas en los últimos años está aumentando la desigualdad y los conflictos sociales y, en particular, la marginación de los pueblos indígenas, que en muchos casos son los legítimos propietarios de las tierras forestales. En este trabajo se analiza el caso de la población purépecha de Cherán, Michoacán, comunidad que en 2011 organizó un levantamiento armado como protesta por la tala ilegal de sus bosques, frente a la indiferencia de las autoridades. A partir de imágenes satelitales Spot, de alta resolución (10 m) se estimó la pérdida anual de la cubierta forestal, entre 2006 y 2012. Utilizando un criterio basado en el NDVI y la firma espectral, se obtuvieron y validaron los mapas de suelo / vegetación, para cada año del período estudiado; la comparación de los mapas anuales permitió construir el mapa de deforestación anual. En total, fueron deforestadas 9069 hectáreas, lo que equivale a $71 \%$ de la superficie vegetal existente en 2006. La mayor parte de la deforestación se produjo entre 2010 y 2011 (2815 ha) y corresponde la zona más cercana al núcleo urbano; muchas zonas taladas también fueron quemadas. Estos resultados permiten dimensionar el problema de la deforestación en Cherán y ayudan a entender la reacción de la comunidad ante la devastación de sus bosques.

Palabras clave: cambio de cobertura, imágenes Spot, Meseta Purépecha, movimientos indígenas.

\section{ABSTRACT}

The devastation of ecosystems in recent years is increasing the inequality and social conflict, and in particular, the marginalization of indigenous people, who in many cases are the rightful owners of the forestland. In this research we analyse the case of the Purepecha town of Cheran, Michoacan, community that in 2011, staged an armed uprising as protest for the illegal logging of their forests, in the face of the indifference of the authorities. The annual loss of forest cover between 2006 and 2012 was estimated by analyzing high resolution satellite images Spot $(10 \mathrm{~m})$, using a criterion based on the NDVI and the spectral signature. Soil / vegetation maps were obtained and validated for each year of the period studied; the comparison of annual maps allowed to generate the map of annual deforestation. In total, 9000 ha were deforested, equivalent to $71 \%$ of the vegetation area existing in 2006. Most deforestation occurred between 2010 and 2011 (2815 ha) and corresponds to the forest nearest the urban core area; many clearcuts were also burned. These results measure the problem of deforestation in Cheran and help understand the community's reaction to the destruction of their forest.

Keywords: land cover change, Spot images, Meseta Purepecha, indigenous movements

\section{INTRODUCCIÓN}

En los últimos 50 años la humanidad ha cambiado los ecosistemas más rápida y extensivamente que en cualquier periodo comparable de la historia. Muchos de estos cambios han sido en respuesta a las necesidades crecientes de comida y agua, así como de madera, fibras y combustibles; la obtención desmesurada de estos recursos tiene consecuencias graves, como la pérdida de biodiversidad, el cambio climático y la degradación de los suelos. Este alto precio por la degradación de los servicios ecosistémicos 
está siendo asumido de manera desproporcionada por los más pobres, lo que está acrecentando la desigualdad y los conflictos sociales (Millenium Ecosystem Assessment, 2005). Mientras las zonas más desarrolladas del planeta han logrado mantener o incrementar sus superficies forestales en la última década, con tasas de cambio entre $1.16 \%$ en los países de Asia del Este, $0.36 \%$ en Europa ( $\sin$ Rusia), $0.28 \%$ en Asia del Sur, $0.13 \%$ en EE.UU. y $0 \%$ en Canadá, en los países menos desarrollados la tendencia es negativa, con $-1.19 \%$ en América Central y entre $-0.45 \%$ y $-0.36 \%$ en América del Sur, África, Asia del Sur y del Este y Oceanía (FAO, 2011). Esta correlación entre el nivel de desarrollo y el de deforestación se encuentra también entre los países de cada región (Redo et al., 2012) y se explica por diferentes factores.

La extracción de madera, la expansión de la agricultura, principalmente de los cultivos permanentes, y la construcción de infraestructura, en particular de transporte, se consideran las causas directas más importantes de la deforestación. Sin embargo, las verdaderas causas son indirectas: de naturaleza económica, demográfica, tecnológica, sociopolítica o cultural y dependen principalmente de las "actitudes de indiferencia pública hacia los entornos forestales" (Geist y Lambin, 2002).

Los gobiernos con débil legitimidad muestran una capacidad limitada para mantener localmente sistemas sustentables de manejo forestal (Bottazzi y Dao, 2013), mientras que aquellos con altos niveles de gobernabilidad (concepto que incluye la estabilidad, la ausencia de violencia, la efectividad y el control de la corrupción (Kauffmann et al., 2012)) se asocian con bajos niveles de deforestación ilegal. Sin embargo en aquellos casos en que las políticas públicas eficientes estimulan la expansión agrícola, descuidando la conservación del medio ambiente, puede haber una pérdida importante de superficie forestal (Ceddia et al., 2014). Así, la falta de regulación en los usos de suelo (Redo et al., 2012) y de coordinación entre las políticas agrícolas y forestales, con la priorización de las primeras, ha fomentado en muchos casos la conversión de tierras forestales a cultivos, con el fin de hacerlas productivas o simple- mente como mecanismo para legitimar su propiedad (Bottazzi y Dao, 2013).

La tenencia de la tierra se señala como un factor importante asociado con la deforestación, sin embargo, no hay una relación directa con el tipo de propiedad, privada o comunal, sino más bien con el nivel de compromiso (y la capacidad real) de los propietarios para limitar la explotación (Bottazzi y Dao, 2013). La tierras comunales son a menudo propiedad de poblaciones indígenas, y en estos casos se ha observado que la probabilidad de deforestación es menor, lo que se explica por el sentimiento de arraigo y respeto de las comunidades por su territorio, que es su espacio natural de vida, base de sus saberes, conocimientos, cultura, identidad, tradiciones y derechos (Barranquero et al., 2010), además de constituir su único patrimonio (Madrid et al., 2009). La falta de apoyo al sector forestal y de respeto hacia las culturas indígenas, aunada a la pobreza de estos grupos de población, que no cuentan con fuentes de empleo en otros sectores, obliga a los dueños de los bosques a elegir entre la sustentabilidad económica de sus familias y la sustentabilidad ecológica de sus bosques.

Un elemento adicional, que intensifica la presión hacia las superficies forestales de los pueblos indígenas en situaciones de débil gobernabilidad, es el control de las tierras forestales por parte de grupos armados ligados a actividades delictivas, como el narcotráfico, ya sea para mantener el dominio del territorio, comercializar madera y minerales de forma ilegal y/o establecer cultivos de drogas. Este fenómeno se ha ido consolidando en los últimos años como uno de los principales factores de la pérdida de bosques tropicales de América Latina, principalmente en los países de producción y tránsito de drogas hacia los Estados Unidos, es decir, desde Colombia hasta México (McSweeney et al., 2014).

En México se vive desde hace varios años una situación de violencia e ingobernabilidad (Casar, 2015), relacionada con el tráfico de drogas y la "guerra" emprendida para combatirlo. Entre las consecuencias de este conflicto, hay que incluir la creciente pobreza y desigualdad social (Hurtado-González y Delgado-Valdez, 2013) y la intensi- 
ficación de la devastación ecológica (McSweeney et al., 2014). En México la mayoría de los bosques pertenecen a comunidades y pueblos indígenas (Madrid et al., 2009); sin embargo, las políticas públicas inadecuadas y la falta de apoyo para la tecnificación y comercialización de los productos forestales, no han permitido el desarrollo de una silvicultura efectiva que permita a estos grupos salir de la situación de pobreza en que se encuentran (DOF, 2014; Navarrete-Linares, 2008), sino que más bien ha incentivado la tala ilegal y ha creado muchos conflictos territoriales entre las comunidades (White y Martin, 2002).

Michoacán es uno de los estados más violentos e inestables del país, por estar en disputa entre varias asociaciones delictivas (Maldonado-Aranda, 2012; Ameth, 2015); a pesar de ser uno de los principales productores agropecuarios, es el octavo estado en índice de marginación y el tercero en expulsión de migrantes hacia los EE. UU. (Fuentes-Díaz y Paleta-Pérez, 2015); al mismo tiempo, es uno de los estados con más municipios indígenas. La población indígena michoacana pertenece a las regiones purépecha (en el centro), nahua (en la sierra-costa) y mazahua-otimí (en el oriente, Reserva de la Mariposa Monarca) (Franco-Mendoza, 1996) y cada una de ellas constituye un claro ejemplo de los problemas descritos. En el presente trabajo se analiza el caso reciente del municipio purépecha de Cherán.

La población purépecha de Cherán sufrió, entre 2006 y 2011, el saqueo sus bosques por parte de grupos armados, ante la indiferencia del gobierno. En respuesta a esta situación, la comunidad organizada protagonizó un levantamiento armado, que la convirtió, en México y el mundo, en el paradigma de la lucha de los pueblos indígenas por sus recursos naturales (Turati, 2012; Fuentes-Díaz y Paleta-Pérez, 2015). A pesar de la importancia social y mediática del tema (el hecho sirvió de referencia para los movimientos de autodefensa que aparecieron en 2013 en diferentes puntos del estado de Michoacán (Pérez-Caballero, 2015)), la superficie deforestada en Cherán no ha sido cuantificada hasta ahora de manera clara y objetiva. Las imágenes proporcionadas por satélites de observación de la Tierra pueden constituir una opción para la cuantificación de la deforestación en este municipio, ya que han probado ser una herramienta de transparencia global en el sector forestal (Gorsevski et al., 2012) y se han utilizado en numerosos estudios de cambio de uso de suelo (Teng et al., 2008).

\section{OBJETIVOS}

El objetivo de este trabajo fue cuantificar la deforestación anual en el municipio de Cherán, entre 2006 y 2012, con el fin de proporcionar información clara y objetiva que contribuya a entender la situación sociopolítica de este municipio en el contexto actual de ingobernabilidad, violencia y pobreza. Se propone una metodología de construcción de mapas consistente en una clasificación no supervisada de imágenes satelitales de alta resolución, utilizando un criterio basado en el NDVI y la firma espectral.

\section{MATERIALES Y MÉTODOS}

\section{Zona de estudio}

El municipio de Cherán, de población indígena y vocación forestal, es el más pequeño de los cinco que conforman la llamada Meseta Purépecha (19³ $38^{\prime}-19^{\circ} 51^{\prime}$ N y $101^{\circ} 52^{\prime}$ - $102^{\circ} 08^{\prime}$ W) del estado de Michoacán de Ocampo, en México. Tiene una extensión territorial de $221.88 \mathrm{~km}^{2}$. Su altitud varía entre los $2200 \mathrm{~m}$ snm y los $3299 \mathrm{~m}$ snm. El clima es templado sub-húmedo con lluvias en verano; la temperatura varía de $12{ }^{\circ} \mathrm{C}$ a $24^{\circ} \mathrm{C}$ y la precipitación pluvial anual total va de $1000 \mathrm{~mm}$ a $1200 \mathrm{~mm}$. Según el Censo de Población y Vivienda del Instituto Nacional de Estadística y Geografía (Inegi, 2005), su población es de 18141 habitantes, repartidos en tres núcleos urbanos: Cherán, Santa Cruz Tanaco y la pequeña comunidad de Casimiro Leco (El Cerecito). La vegetación característica es el bosque de pino (Pinus sp.), principalmente en las zonas montañosas; en la parte norte del municipio hay zonas bajas con vegetación de transición, principalmente arbustos y encinos (Quercus sp.).

Como otros municipios del estado, sufrió desde los años 90s la tala clandestina de sus bosques, frente a la 
indolencia de las autoridades estatales y federales. En los últimos años el problema se agravó, por la combinación de diferentes factores: la falta de empleo, la aplicación de equipo especializado en corte y aserrío, la corrupción en la entrega de autorizaciones para el uso forestal de los bosques, el aumento del tráfico y consumo de drogas en la población joven, así como la penetración de la delincuencia en diferentes niveles del gobierno estatal y municipal, incluyendo la policía. Esta situación propició la proliferación de talamontes del propio municipio (se señala a los pobladores de Tanaco y El Cerecito) y de municipios cercanos (Nahuatzen, Uruapan, Zacapu y Chilchota), responsables de la extracción diaria de toneladas de madera y del aumento de las extorsiones a los habitantes. El 15 de abril de 2011, después de meses de enfrentamientos entre los talamontes y la población, los cheranenses decidieron asumir la defensa armada de su territorio y negarse a la celebración de comicios electorales en el municipio, previstos para el 11 de noviembre de ese mismo año (Ruíz, 2011; Turati, 2012).

\section{Imágenes satelitales}

Para la realización del trabajo se utilizaron en total 13 imágenes del satélite Spot 5: 9 multibanda $(10 \mathrm{~m})$ y 4 pancromáticas $(2.5 \mathrm{~m})$, con fechas de adquisición comprendidas entre 2004 y 2012. Las imágenes satelitales fueron concedidas para este trabajo en el marco del convenio ERMEXS - UMSNH 2012. En todos los casos se trata de imágenes correspondientes a la época de secas.

\section{Metodología}

El análisis de las imágenes se realizó con el programa informático ENVI 4.8 (Exelis, Visual Information Solutions, Inc.).

\section{Preprocesamiento}

Las imágenes multibanda fueron calibradas con respecto a las ganancias de los sensores, para pasar de valores digitales brutos a radianzas (valores proporcionados por Spotimage). Las imágenes calibradas se corrigieron atmosféricamente con el modelo FLAAHS, para obtener reflectancias. Para cada fecha, se recortó la zona de estudio, considerando el límite oficial del municipio de Cherán, proporcionado por el Inegi.

Las imágenes de los años 2004, 2005 y 2006 no contienen el municipio completo. Dado que los problemas de deforestación son posteriores al 2006 y no hay cambios importantes en la cobertura entre estos años, se construyó un mosaico con las tres imágenes. Este mosaico constituye la imagen de referencia de la situación inicial del bosque y se considerará como la imagen de 2006.

Las imágenes del municipio de cada año se hicieron coincidir pixel a pixel con el mosaico de la fecha inicial, utilizando más de 300 puntos de control en cada caso, para lograr un error inferior a 1 pixel (función WARP de ENVI).

\section{Clasificación}

Se consideraron dos tipos de cobertura generales: suelo, que incluye tanto las zonas de suelo desnudo, como con poca vegetación, y vegetación, que corresponde principalmente a las zonas de bosque de pino y pino-encino, pero también de especies arbustivas y de matorral. Dado que las imágenes corresponden a época de secas, las parcelas de cultivo carecen de vegetación. Trabajar con un número pequeño de coberturas permite obtener mapas de mayor precisión (Teng et al., 2008). En el caso del municipio de Cherán, donde la deforestación se produjo de forma rápida y el bosque denso pasó a ser suelo desnudo, es suficiente separar de manera general el suelo y la vegetación. Estos dos tipos de cobertura tienen firmas espectrales características y contrastantes (Guyot, 1997; Jones y Vaughan, 2010): Una vegetación densa presenta una reflectancia baja en el visible, con un máximo relativo en el verde y un mínimo en el rojo, en contraste con una reflectancia muy alta en el infrarrojo cercano (NIR), con un mínimo relativo en el infrarrojo medio (SWIR), en las bandas de absorción de la luz por el agua contenida en las hojas; su NDVI (índice de la diferencia normalizada, calculado como la diferencia entre las reflectancias en el rojo y el NIR, dividida por su suma (Chen, 1996)) es cercano a 1. Por su parte, un suelo 
desnudo presenta una reflectancia creciente desde el visible al NIR y SWIR, y un valor de NDVI cercano a 0 .

Para cada fecha se realizó una clasificación no supervisada de 20 clases, con un algoritmo k-means (Tou y González, 1974; Campbell, 2002; Lu y Weng, 2007; Shi y Ding, 2011; Baldeck y Asner, 2013). Una vez establecidas las clases, cada una de ellas se asignó a uno de los tipos de cobertura o categorías del mapa final. Con el fin de garantizar que los mapas obtenidos serían comparables entre sí, se definió un criterio objetivo de asignación de las clases (Campbell, 2002; Schulz et al., 2010; Sexton et al., 2013), para lo cual se obtuvo la firma espectral y el NDVI promedios de cada una de ellas. Entre las clases de cada año, ordenadas en orden creciente de NDVI, se estableció la separación entre los dos tipos de cobertura a partir de la observación de las firmas espectrales. Adicionalmente se realizó la verificación visual sobre las imágenes pancromáticas. Como resultado se obtuvieron los mapas anuales de cobertura suelo/vegetación, que se validaron con regiones de interés (entre 5000 y 8000 pixeles / clase / año, para los que resultaba evidente su pertenencia a uno de los tipos de cobertura) tomadas sobre las imágenes multi- banda, con referencia a las imágenes pancromáticas correspondientes.

\section{Análisis de los cambios}

Se utilizó un árbol de clasificación para comparar, pixel a pixel, los mapas anuales, con el fin de determinar la superficie deforestada cada año, entendiendo como tal aquella que, habiendo sido clasificada como vegetación en todos los años anteriores, fue clasificada como suelo ese año. De esta forma se evitó considerar como reforestadas las zonas en las que se recuperó algo de vegetación, si bien, por el poco tiempo transcurrido desde la deforestación, no se puede considerar que se trate de bosque. Se obtuvo así mismo la superficie deforestada total en el periodo estudiado, tanto en valor absoluto (ha), como relativo a la superficie vegetal inicial (vegetación en el mapa 2006).

\section{RESULTADOS Y DISCUSIÓN}

La Figura 1 muestra los recortes correspondientes a 2006 y 2011; se observa la importante pérdida de bosque entre las dos fechas.
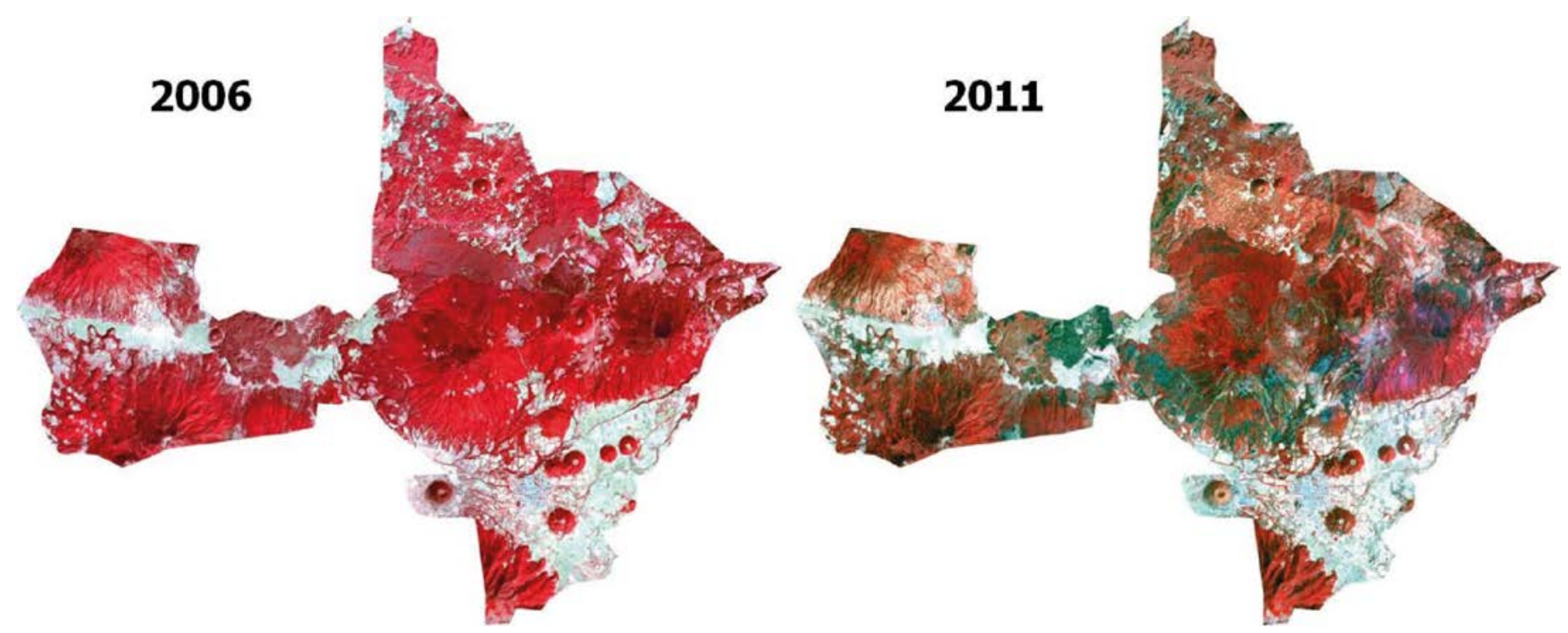

Figura 1. Imágenes Spot $5(10 \mathrm{~m})$ del municipio de Cherán correspondientes a 2006 y 2011, visualizadas en falso color (R: banda 3 (infrarrojo cercano, NIR), G: banda 2 (rojo), B: banda 1 (verde)). La vegetación aparece en tono rojo, el suelo desnudo en cyan y las zonas deforestadas y en algunos casos quemadas, en azul verdoso. 
Los NDVIs promedio de las 20 clases obtenidas con una clasificación no supervisada ( $k$-means) de las imágenes preprocesadas de cada año (2006 a 2012) están en un intervalo de 0.2 a 0.9 , siendo los valores más altos los correspondientes a los años en los que las imágenes son de los meses de invierno y los valores más bajos los del año 2011.

Se analizaron las firmas espectrales de cada una de las clases. Se observó que las clases con NDVI bajo presentaban una firma espectral característica de suelo, es decir, con un factor de reflectancia creciente con la longitud de onda. A partir de cierta clase (o cierto valor de NDVI), diferente para cada año, las firmas espectrales cambian, y se vuelven más parecidas a las de una vegetación, es decir, con una subida brusca entre el rojo y el NIR y una caída suave entre el NIR y el SWIR (no se observa un máximo en el verde con respecto al rojo, probablemente por la insuficiente corrección atmosférica, asociada a la falta de banda azul en las imágenes Spot 5). En algunos casos (2006, 2009, 2010), la separación se produce entre clases con NDVI similares, pero que presentan diferente firma espectral, lo que apoya la utilización del doble criterio.

La figura 2 muestra los mapas correspondientes a los dos tipos de cobertura, para cada año. La validación de estos mapas con regiones de interés (ROI) (una región por tipo de cobertura y por fecha) arrojó en todos los casos una precisión total de más de $90 \%$ (entre $92.76 \%$ para
2011 y $98.87 \%$ para 2010). En los mapas anuales se observó que hasta 2009 la mayor parte del municipio está cubierta de vegetación, salvo el centro-oeste y el sur, donde predominan las zonas agrícolas. En 2010 se observa una importante disminución de la cobertura vegetal, en particular en el centro y el norte del municipio. En 2011 se produce la mayor pérdida de bosque. En el mapa 2012 se observa la pérdida de algunas zonas de bosque y la recuperación de otras; esto último podría corresponder a un pico de verde (peak of green), fenómeno consistente en la aparición de abundante vegetación baja el año siguiente de un incendio forestal (Vogelmann et al., 2011).

Comparando los mapas anuales consecutivos con un árbol de decisión, se obtuvo el mapa de cambios de la figura 3; los valores se muestran en la tabla 1. El periodo entre 2008 y 2009 fue el de menor deforestación, seguido por el periodo 2011 a 2012, cuando la comunidad tenía el control de la zona. En el año 2011 se dio la mayor pérdida absoluta, que además corresponde a la superficie más cercana al centro urbano de Cherán. En total se perdieron 9069.35 ha, en 6 años, lo que representa un promedio de 1500 ha/año y corresponde a un porcentaje de cambio de bosque de $71.24 \%$ de las 12730.48 ha de bosque que tenía Cherán en 2006, equivalente a una tasa de cambio de $-18 \%$. El porcentaje de superficie afectada en Cherán es similar a la pérdida de más de $74 \%$ de la cobertura forestal que se dio en el estado de Michoacán entre 1974 y

TAвla 1: Superficie deforestada anualmente entre 2006 y 2012, en el municipio de Cherán, Mich., así como el valor acumulado cada año y el porcentaje que representan estos valores con respecto a superficie de bosque en la fecha inicial de referencia (2006).

\begin{tabular}{ccccc}
\hline Periodo & $\begin{array}{c}\text { Superficie deforestada } \\
\text { (ha) }\end{array}$ & $\begin{array}{c}\text { Superficie deforestada } \\
\text { acumulada (ha) }\end{array}$ & $\begin{array}{c}\text { \% Superficie defores- } \\
\text { tada/vegetación 2006 }\end{array}$ & $\begin{array}{c}\text { \% Superficie deforestada } \\
\text { acumulada/vegetación 2006 }\end{array}$ \\
\hline De 2006 a 2007 & 1566.29 & 1566.29 & 12.30 & 12.30 \\
De 2007 a 2008 & 1125.71 & 2692.00 & 8.84 & 21.15 \\
De 2008 a 2009 & 665.94 & 3357.94 & 5.23 & 26.38 \\
De 2009 a 2010 & 1794.44 & 5152.38 & 14.10 & 40.47 \\
De 2010 a 2011 & 2815.02 & 7967.40 & 22.11 & 62.59 \\
De 2011 a 2012 & 1083.54 & 9050.94 & 8.51 & 71.10 \\
\hline
\end{tabular}



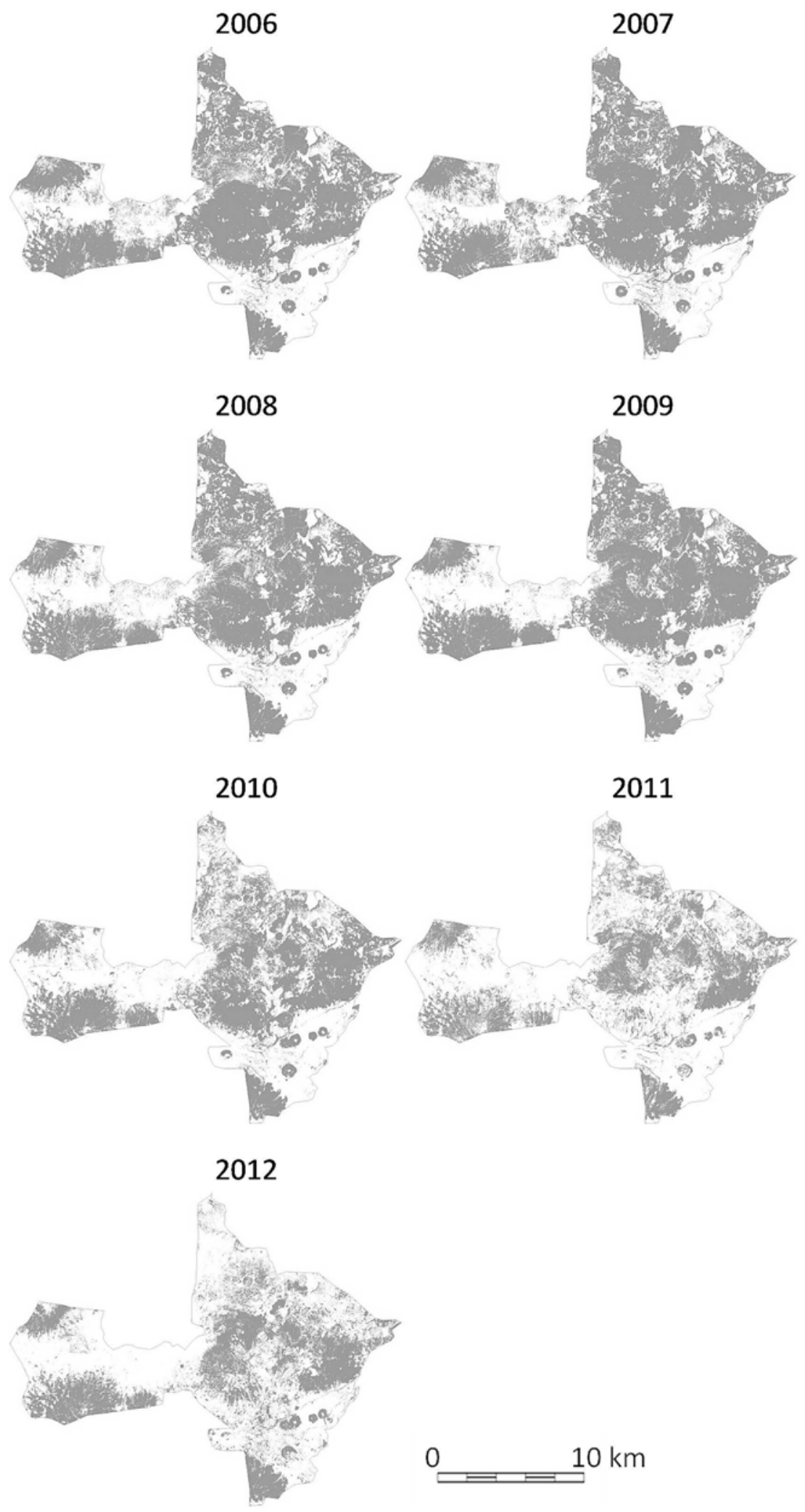

Figura 2. Mapas de cobertura suelo (blanco) / vegetación (gris) del municipio de Cherán, Mich. Para los años 2006 a 2012. 

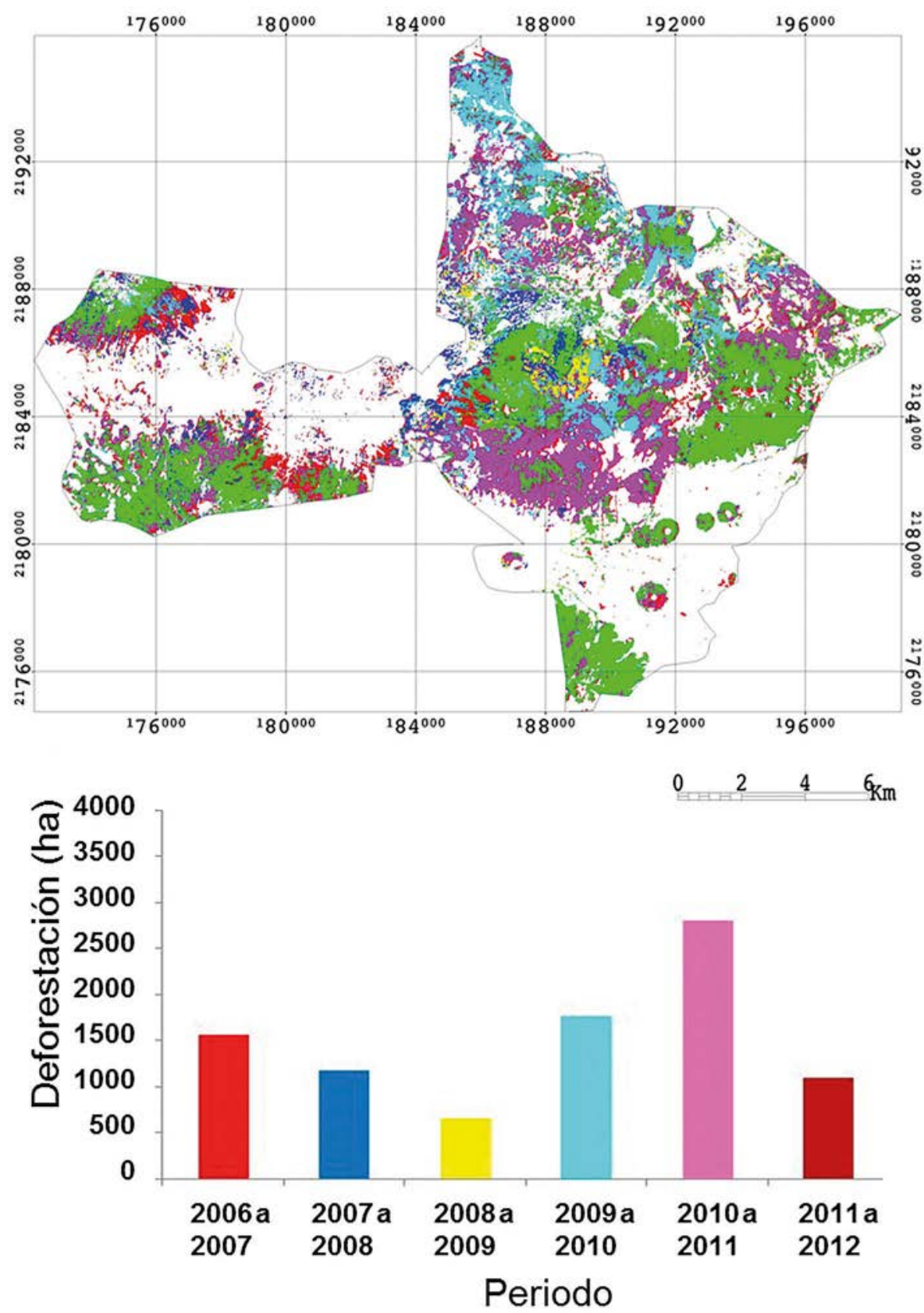

Figura 3. Mapa de deforestación anual en el municipio de Cherán, Mich., entre los años 2006 y 2012. En verde la vegetación no deforestada presente en 2012 (3661 ha).

Generado con datos provenientes de la "ERMEXS-UMSNH 2O12".

2008 por la expansión del cultivo de aguacate; $40 \%$ del bosque perdido pertenecía a la Meseta Purépecha, donde se encuentra el principal centro productivo (Tejera et al., 2013). Hasta ahora este proceso de "aguacatización" no se ha dado en Cherán ni en los municipios circunvecinos, porque las condiciones agroecológicas no son las más aptas para este cultivo; sin embargo, no se descarta la posibilidad de que se intente introducir en alguna zona, debido a su alto rendimiento. En Cherán se produjo, en seis años, una deforestación equivalente (superior a 70\%) 
a la que se estima que habrán acumulado entre 1950 y 2050, a nivel mundial, diferentes biomas, como el bosque y matorral mediterráneos, el bosque templado, así como el bosque seco caducifolio, las sabanas, los pastizales, los matorrales y los bosques de coníferas tropicales y subtropicales (Millenium Ecosystem Assessment, 2005).

Como en la mayoría de los casos de deforestación, se pueden identificar tres o cuatro causas indirectas o subyacentes que están controlando dos o tres causas directas (Geist y Lambin, 2002): la extracción de madera para su comercialización y, quizás en algunas zonas del municipio, la intención de extender la agricultura, están dirigidas por factores políticos o institucionales (en un contexto de ingobernabilidad y delincuencia), así como económicos (por la falta de trabajo y la situación de pobreza), tecnológicos (como el uso de motosierras) y culturales (ligados al complejo contexto de las poblaciones indígenas) (FrancoMendoza, 1996).

Muchas de las zonas taladas en Cherán fueron también quemadas, en particular en 2011; según la población, "los talamontes quemaban con el objetivo de causar miedo para facilitar su huída”. En la figura 4 se muestran, como ejemplo del proceso de deforestación, los recortes de imágenes pancromáticas de dos zonas del municipio, en 2005 (con arbolado denso, no perturbado), 2010 (con partes deforestadas, recién quemadas) y 2011 (la zona deforestada se ha extendido y se está quemando; se pueden apreciar las nubes de humo presentes en el momento del paso del satélite, así como los brillos en el suelo por las cenizas aún calientes). Esto evidencia que se trata de un proceso paulatino de destrucción del bosque, que además de la tala incluye quema. Si bien el fuego favorece la germinación de las semillas de algunos árboles y propicia el crecimiento del pasto que sirve de alimento al ganado, sus efectos destructivos sobre la biodiversidad son enormes: reduce rápidamente la vegetación natural, debilita a las especies forestales, afecta la reproducción de los organismos silvestres, compacta el suelo y elimina la hojarasca de la superficie, lo que afecta el ciclo hidrológico, mineraliza la materia orgánica, acelera la descomposición del carbono en el suelo y su liberación a la atmósfera, etc.
(Orozco-Hernández et al., 2011). En 2013, ChalachaGaona y Rendón-Carmona (2014) realizaron un estudio comparativo entre zonas taladas, y taladas y además quemadas, en el municipio de Cherán, encontrando importantes diferencias: en los sitios talados, 98\% de los árboles que quedaban (principalmente encinos) y $14 \%$ de los tocones, estaban vivos, en contraste con $57 \%$ y $4 \%$, respectivamente, de los sitios talados y quemados; en cuanto a la regeneración, en los sitios talados se contabilizaron 6 plantas arbustivas y 0.8 plántulas de especies arbóreas por metro cuadrado, en contraste con 4 y 0.3 , respectivamente, en los sitios talados y quemados. Estos datos reflejan una situación ecológica muy crítica, principalmente en las zonas quemadas.

Entre los aspectos más relevantes del caso Cherán destaca la negativa de la comunidad a celebrar los comicios electorales de noviembre 2011 y a aceptar un gobierno local partidista. Fue especialmente significativo el hecho de que la Sala Superior del Tribunal Electoral del Poder Judicial de la Federación (TEPJF) (el Instituto Electoral de Michoacán (IEEM) se declaró incompetente) resolviera a favor del municipio de Cherán sobre la protección de sus derechos políticoelectorales para ejercer la libre determinación y establecer un Concejo Mayor como máximo órgano de gobierno (Ibarra y Castillo-Vaquera, 2014). Si bien los principios rectores de los derechos de los pueblos indígenas, entre ellos la libre determinación, el derecho a la consulta previa, libre e informada y los usos y costumbres, están reconocidos en la Constitución Política Mexicana desde 2001, así como en tratados internacionales firmados por México, en la práctica estos derechos no se ejercen en su totalidad. Esta acción del TEPJF fue vista como un intento de apertura y respeto hacia los pueblos indígenas y, desde entonces, otras comunidades han tenido mayor acercamiento con el TEPJF y han comenzado a intentar esta vía judicial para ejercer su derecho al autogobierno (Bárcenas, 2016).

\section{CONCLUSIONES}

En el presente trabajo, basado en el análisis de imágenes satelitales Spot de alta resolución, se pudo constatar la pérdida de superficie forestal en el municipio de Cherán, año 

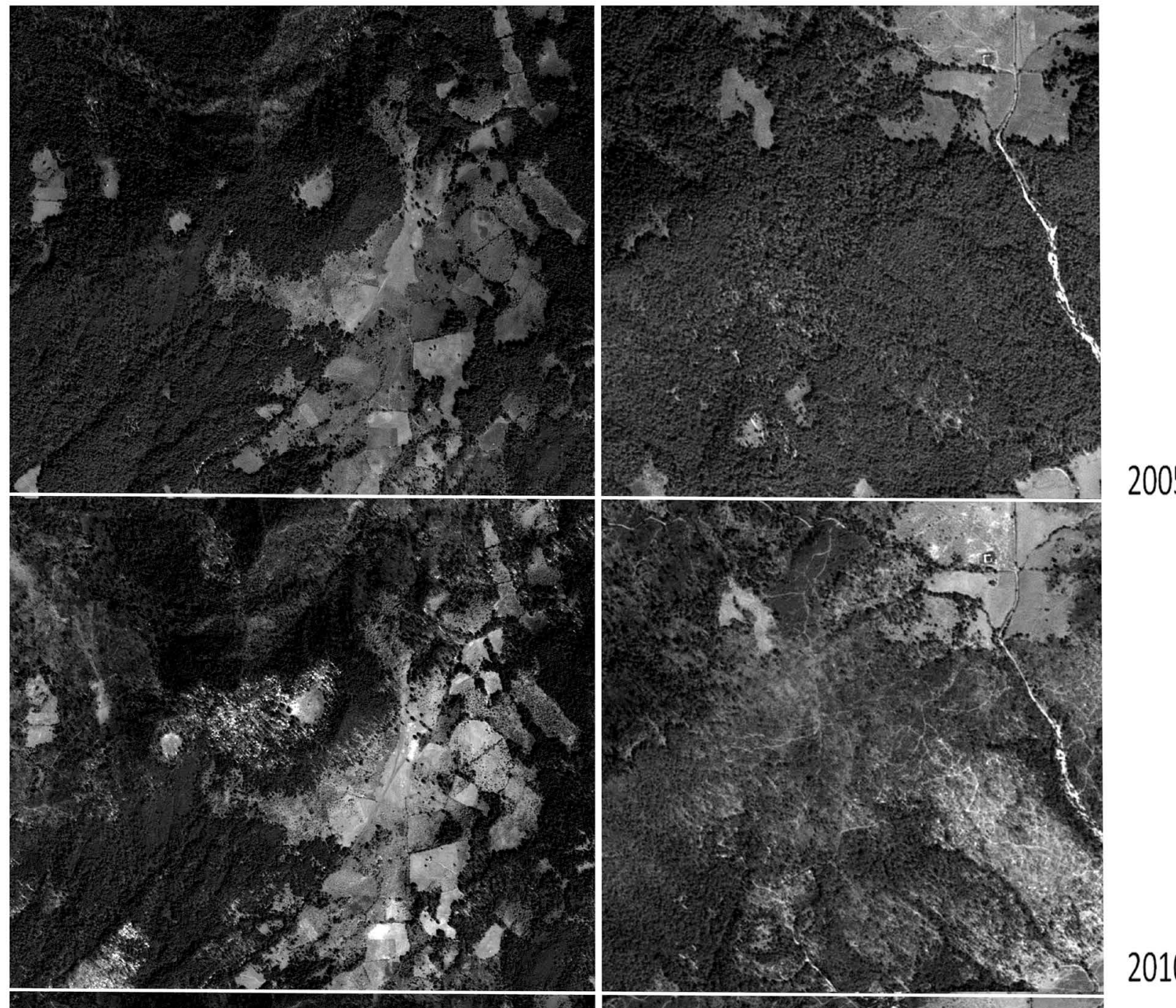

2005
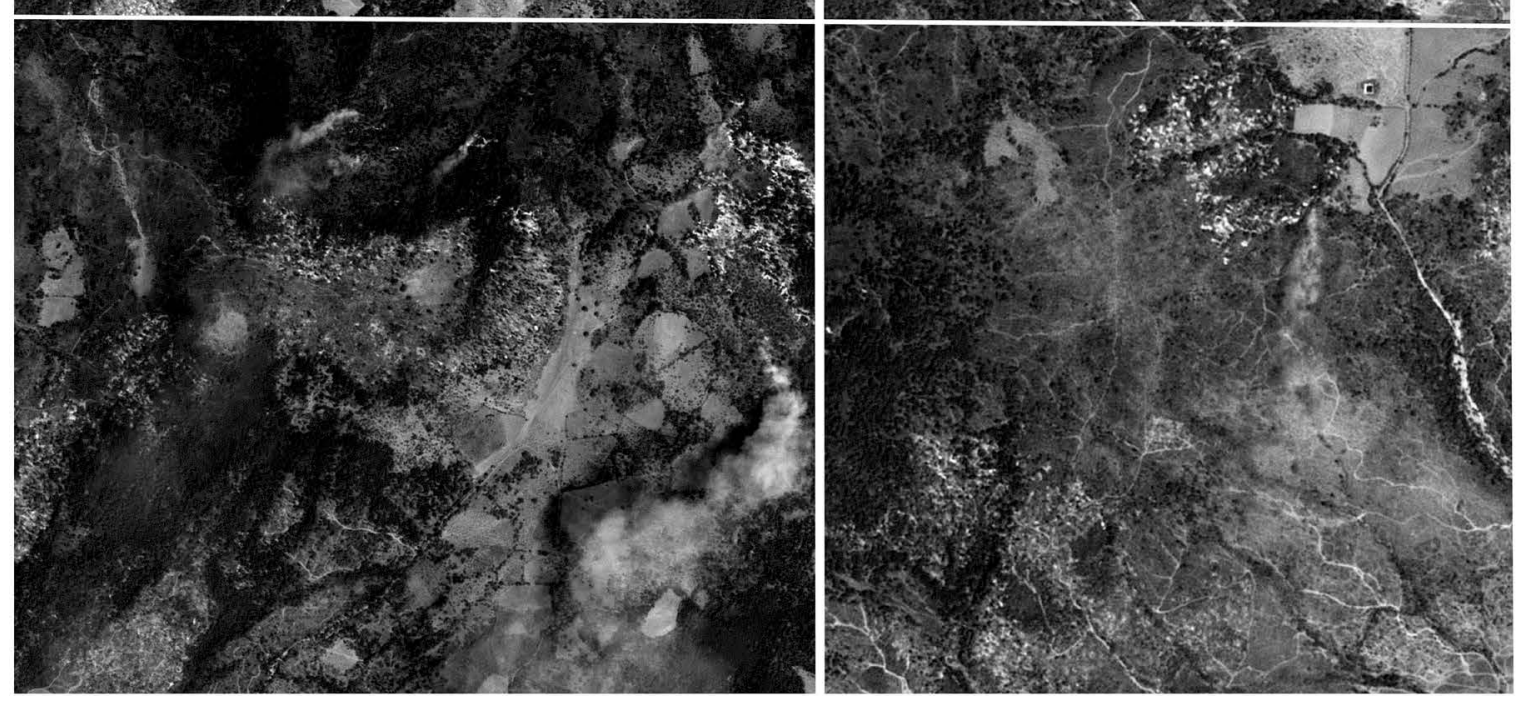

Figura 4. Fragmentos de imágenes pancromáticas Spot 5 (2.5 m) de los años 2005, 2010 y 2011, correspondientes a dos zonas dentro del municipio de Cherán, Mich., como ejemplo del proceso de deforestación y quema del bosque. Se observan nubes de humo y cenizas aún calientes.

(c) CNES 2012, producida por ERMEXS-UMSNH bajo licencia de "SPOT IMAGE, S. A." 
con año entre 2006 y 2012, principalmente en 2011 (2815 ha). En el periodo estudiado la superficie vegetal total pasó de 12730 ha a 3661 ha, es decir quedó reducida a menos de un tercio de su extensión inicial. En las imágenes se constata que las zonas deforestadas fueron después quemadas, lo que puede tener implicaciones en el proceso de restauración. Se pueden identificar como posibles causas de la deforestación la comercialización ilegal de madera y la expansión de la agricultura, en el complejo contexto de ingobernabilidad, delincuencia y pobreza en el que se encuentran las poblaciones indígenas de Michoacán. Se desconoce quién es responsable de la tala y la quema de los bosques y las autoridades no parecen tener interés en investigarlo; mientras tanto, la comunidad está concentrada en realizar un gran esfuerzo por restaurar el bosque y repensar su futuro.

\section{RECONICIMIENTOS}

Las imágenes Spot utilizadas fueron proporcionadas en el marco del convenio ERMEXS - UMSNH 2012.

\section{REFERENCIAS}

Ameth, E. 2015. Los cárteles más violentos de México. Forbes México, 10 abril 2015. Obtenido en http://www.forbes. com.mx/los-carteles-mas-violentos-de-mexico/

Baldeck, C.A. y G.P. Asner. 2013. Estimating vegetation beta diversity from airborne imaging spectroscopy and unsupervised clustering. Remote Sensing 5:2057-2071. doi:10.3390/rs5052057

Bárcenas, E. Entrevista publicada por Agencia Quadratín en: https://www.quadratin.com.mx/regiones/Desde-casoCheran-comunidades-tuvieron-mas-acercamiento-TEPJF/, 12 de enero 2016

Barranquero, A., B. Rivela-Carballal, C. Tangianu, M. Mantini, M. Di Donato, N. Del Viso y S. ÁlvarezCantalapiedra. 2010. Cultura, ambiente y cooperación internacional al desarrollo. Líneas estratégicas de acción cultural en materia ambiental. $1^{\text {a }}$ ed. CIP-Ecosocial (FUHEM) Madrid. 143 p. Obtenido en http://www.fuhem. $\mathrm{com} / \mathrm{media} /$ ecosocial/File/Proyecto $\% 20$ Cultura $\% 20$ y\%20Ambiente/CULTURA\%20Y\%20AMBIENTE.pdf
Bottazzi, P. y H. Dao. 2013. On the road through the Bolivian Amazon: a multi-level land governance analysis of deforestation. Land Use Policy 30(1):137-146. doi:10.1016/j. landusepol.2012.03.010

Campbell, J.B. 2002. Introduction to Remote Sensing. : The Guilford Press. Nueva York, EUA. 621 p.

Casar, M.A. 2015. México: Anatomía de la corrupción. 1ª ed. Centro de Investigación y docencia Económicas (CIDE), Instituto Mexicano para la competitividad A.C. (IMCO). México DF. 64 p. Obtenido en http://www.cide.edu/wpcontent/uploads/2015/05/MXAnatomiadelaCorrupcion_ MariaAmparoCasar.pdf

Ceddia, M.G., N.O. Bardsley, S. Gomez-y-Paloma y S. Sedlacek. 2014. Governance, agricultural intensification, and land sparing in tropical South America. Proceedings of the National Academy of Sciences 111(20):7242-7247. doi:10.1073/pnas.1317967111

Chalacha-Gaona, A. G. y Rendón-Carmona H., 2014. Efectos provocados por el corte y fuego en bosques templados: el caso de Cherán, Michoacán. Memorias del VI Congreso Forestal Latinoamericano. Morelia, Michoacán, México, 20 - 24 Octubre 2014.

Chen, J.M. 1996. Evaluation of vegetation indices and a modified simple ration for Boreal applications. Canadian Journal of Remote Sensing 22:229-241. Obtenido de http:// f t p 2 . cits.nrcan.gc.ca/pub/geot t/es s_ pubs/218/218303/1526.pdf

DOF (Diario Oficial de la Federación). Programa especial de los Pueblos Indígenas 2014-2018. 30/04/2014. 37 p. Obtenido en http://dof.gob.mx/nota_detalle.php?codigo=5343 116\&fecha $=30 / 04 / 2014$

FAO (Organización de las Naciones Unidas para la Alimentación y la Agricultura). 2011. State of the World's Forest. 164 p. Obtenido en http://www.fao.org/docrep/013/ i2000e/i2000e.pdf

Fuentes-Díaz, A. y G. Paleta-Pérez. 2015. Violencia y autodefensas comunitarias en Michoacán, México. Íconos. Revista de Ciencias Sociales 53:171-186. doi:10.17141/ iconos.53.2015.1702

Franco-Mendoza, M. 1996. La cultura de las etnias michoacanas y su participación en el desarrollo social. Relaciones 
63/64:29-48. Obtenido en : http://www.colmich.edu.mx/ relaciones 25/index.php/numeros-anteriores/10 articulos/1076-articulo-64-63-la-cultura-de-las-etniasmichoacanas-y-su-participacion-en-el-desarrollo-social

Geist, H.J. y E.F. Lambin. 2002. Proximate causes and underlying driving forces of tropical deforestation. BioScience 52(2):143-150. doi:10.1016/j.forpol.2014.05.007

Gorsevski, V., E. Kasischke, J. Dempewolf, T. Loboda y F. Grossmann. 2012. Analysis of the impacts of armed conflict on the Eastern Afromontane forest region on the South Sudan - Uganda border using multitemporal Landsat imagery. Remote Sensing of Environment 118:10-20. doi:10.1016/j.rse.2011.10.023

Guyot, G. (1997). Climatologie de l'environnement: De la plante aux écosystèmes. Masson. Paris, Francia, 505 p.

Hurtado-González, L.E. y J.L. Delgado-Valdez. 2013. La guerra contra la delincuencia organizada durante el sexenio 2006-2012 y el respeto a los derechos humanos en México. Investigación Universitaria Multidisciplinaria: Revista de Investigación de la Universidad Simón Bolivar 12:53-68. Obtenido en http://dialnet.unirioja.es/ejemplar/369431

Ibarra, M.I. y Castillo-Vaquera. 2014. Las elecciones de Cherán: usos y costumbres excluyentes. Revista Mexicana de Derecho Electoral 5:263-283. Obtenido en: http://biblio.juridicas.unam.mx/revista/pdf/DerechoElectoral/5/ej/ej9.pdf

Inegi (Instituto Nacional de Estadística y Geografía). 2005. II Conteo de Población y Vivienda. Consultado el 10-022013 en http://www.inegi.org.mx/Sistemas

Jones, H.G. y R.A. Vaughan. 2010. Remote sensing of vegetation. Principles, techniques, and applications. Oxford University Press. Nueva York, EUA., Kaufmann, D., A. Kraay y M. Mastruzzi. 2009. Governance matters VIII: aggregate and individual governance indicators, 19962008. World Bank policy research working paper, (4978). Obtenido en http://www.estafaluz.com/documentos/ estafa/worlwide_gobernance_indicators_1996_2008.pdf

Lu, D., y Q. Weng. 2007. A survey of image classification methods and techniques for improving classification performance. International Journal of Remote Sensing 28(5):823-870. doi:10.1080/01431160600746456D
Madrid, L., J.M. Núñez, G. Quiroz e Y. Rodríguez. 2009. La propiedad social forestal en México. Investigación ambiental 1(2):179-196. Obtenido en http://www2.inecc. gob.mx/publicaciones/download/627.pdf\#page $=68$

Maldonado-Aranda, S. 2012. Drogas, violencia y militarización en el México rural. El caso de Michoacán. Revista mexicana de sociología 74(1):5-39. Obtenido en http://www. scielo.org.mx/pdf/rms/v74n1/v74n1a1.pdf

McSweeney, K., E.A. Nielsen, M.J. Taylor, D.J. Wrathall, Z. Pearson, O. Wang, y S.T. Plumb. 2014. Drug policy as conservation policy: narco-deforestation. Science 343(6170): 489-490. doi: 10.1126/science. 1244082

Millenium Ecosystem Assessment. 2005. Ecosystems and human well-being synthesis. Island Press. Washington, DC. Obtenido en http://www.millenniumassessment.org/ documents/document.356.aspx.pdf

Navarrete-Linares. 2008. Los pueblos indígenas de México. $1^{\mathrm{a}}$ ed. Comisión Nacional para el Desarrollo de los Pueblos Indígenas. México DF. 140 p. Obtenido en http://www. cdi.gob.mx.

Orozco-Hernández, M.E., P. Mireles-Lezama, M.E. ValdezPérez y V. Peña-Majarrez. 2011. Incendios forestales y degradación de los ecosistemas terrestres: impactos locales y emisiones globales. Exploración de la situación en el Estado de México. Revista Geográfica de América Central Número Espacial EGAL. Pérez-Caballero, J. 2015. Autodefensas michoacanas, variante regional de la «guerra al narcotráfico» en México. Revista CIDOB d'afers internacionals, 110:165-188. Obtenido en http://www. raco.cat/index.php/RevistaCIDOB/article/ view/299154/388455

Redo, D.J., H.R. Grau, T.M. Aide y M.L. Clark. 2012. Asymmetric forest transition driven by the interaction of socioeconomic development and environmental heterogeneity in Central America. Proceedings of the National Academy of Sciences 109(23):8839-8844. doi:10.1073/pnas. 1201664109

Ruíz, J. 2011. El caso Cherán. Publicado en Zoom Politikon de LaHuesuda.com el 12 de Mayo de 2011. Consultado en http://espressodopio.wordpress.com/2011/05/12/el-casocheran/ el 16 de Octubre 2014. 
Schulz, J.J., L. Cayuela, C. Echeverria, J. Salas y J.M. Rey-Benayas. 2010. Monitoring land cover change of the dryland forest landscape of Central Chile (1975-2008). Applied Geography30:436-447.doi:10.1016/j.apgeog.2009.12.003

Sexton, J.O., D.L. Urban, M.J. Donohue y C. Song. 2013. Longterm land cover dynamics by multi-temporal classification across the Landsat-5 record. Remote Sensing of Environment 128:246-258. Obtenido en http://dx.doi.org/10. 1016/j.rse.2012.10.010

Shi, W. y H. Ding. 2011. A probability model based method for land cover change detection using multi-spectral remotely sensed images. Photogrametrie-Fernerkundung-Geoinformation, 4:271-280. doi: 10.1127/1432-8364/2011 10088

Tejera H, B., A. Santos O., H. Santamaría Q., T. Gómez M. y C. Olivares V. 2013. El oro verde en Michoacán: ¿un crecimiento sin fronteras? Acercamiento a la problemática y retos del sector aguacatero para el Estado y la sociedad. Economía y sociedad. Crecimiento económico y políticas públicas 29:15-40. Obtenido en http://148.216.28.15/ publicaciones/rev_ecosoc/wp-content/uploads/2014/04/ EyS_29.pdf

Teng, S.P., Y.K. Chen, K.S. Cheng y H.C. Lo. 2008. Hypothesis-test-based land cover change detection using multitemporal satellite images: A comparative study. Advances in Space Research 41:1744-1754. doi:10.1016/j.asr.2007. 06.064
Tou, J.T.y R.C. González. 1974. Pattern Recognition Principles. Addison-Wesley Publishing Company. Reading, Massachusetts, EUA: Turati, M. 2012. Cherán y su rebelión contra la mafia michoacana. Proceso, 1864. Consultado en http://www.proceso.com.mx/314688/cheran-y-su-rebelion-contra-la-mafia-michoacana el 2 de febrero de 2016 Vogelmann, J.E., J.R. Kost, B. Tolk, S. Howard, K. Short, X. Chen, C. Huang, K. Pabst y M. G. Rollins. 2011. Monitoring landscape change for LANDFIRE using multi-temporal satellite imagery and ancillary data. IEEE Journal of Selected Topics in Applied Earth Observations and RemoteSensing 4(2):252-264. doi: 10.1109/JSTARS.2010. 2044478

White, A. y A. Martin. 2002. ¿De quién son los bosques del mundo? Tenencia forestal y bosques públicos en transición. 1a ed. Forest Trends, Center of International Environmental Law, Washington, DC. 42 p. Obtenido en http://www.ccmss.org.mx/descargas/dequienson.pdf

Manuscrito recibido el 27 de octubre de 2014. Aceptado el 3 de febrero de 2016.

Este documento se debe citar como:

España-Boquera, M.L. y O. Champo-Jiménez. 2016. Proceso de deforestación en el municipio de Cherán, Michoacán, México, (20062012). Madera y Bosques 22(1):141-153. 